\title{
A natureza do financiamento influencia na interação universidade-empresa no Brasil?*
}

\author{
Márcia Siqueira Rapini \\ Universidade Federal de Minas Gerais, Belo Horizonte (MG), Brasil \\ Vanessa Parreiras de Oliveira \\ Universidade Estadual de Campinas, Campinas (SP), Brasil \\ Fábio Chaves do Couto e Silva Neto \\ Universidade Estadual de Campinas, Campinas (SP), Brasil
}

Recebido: 23/01/2012 Versão Revisada (entregue): 23/10/2012 Aprovado: 30/10/2012

\begin{abstract}
RESUMO
O objetivo deste artigo é investigar se a natureza da fonte de financiamento influencia na interação universidade-empresa no Brasil em termos dos modos de interação e da motivação para a colaboração. Para tanto, utilizou-se uma base de dados que envolve 319 questionários respondidos pelos responsáveis pelas atividades de pesquisa e desenvolvimento e/ou pelas interações com universidades e institutos públicos de pesquisa (IPPs) em empresas localizadas no Brasil, que apresentaram interação com grupos de pesquisa de universidades/IPPs. São analisadas as empresas que financiaram com recursos próprios os projetos em colaboração com universidades/IPPs, num total de 135, e aquelas que financiaram a interação com uma composição de fontes privadas e públicas, totalizando 94 . As análises apontam que a natureza do financiamento parece não influenciar nos modos de interação, mas sim nos objetivos (ou motivação) da cooperação entre empresas e universidades/IPPs.
\end{abstract}

Os autores agradecem o apoio da Fapemig e do CNPq, bem como os comentários dos pareceristas que enriqueceram a análise dos dados. 
Márcia Siqueira Rapini, Vanessa Parreiras de Oliveira, Fábio Chaves do Couto e Silva Neto

PalaVRas-CHAVE | Interação Universidade-Empresa; Financiamento; BR Survey; Pintec

Código JEL | O30

Does the funding source matter in university-firms interaction in Brazil?

Abstract

The aim of this paper is to investigate if funding sources of university-firms interactions influence modes of interactions and motivation in Brazil. To this end, we used a database involving 319 questionnaires answered by those responsible for research and development ( $R$ $\& D)$ activities and/or by interactions with universities and public research institutes (PRIs) in enterprises located in Brazil, which interacted with research groups of Brazilian universities or PRIs. We analyzed the set of 135 firms that financed with 100\% of own resources their interactions with universities/PRIs and 94 firms that financed the interaction with a composition of public and private sources. The results suggest that the funding sources do not influence modes of university-firms interactions, but do in their objectives or motivation.

KEYWORDS | University-Firms Interactions; Funding; BR Survey; Innovation Survey

JEL-Code $\mid$ O30

\section{Introdução}

As interações com universidades/IPPs são apontadas na literatura como importantes fontes de conhecimento para o processo inovativo nas empresas. A pesquisa acadêmica fornece compreensões e técnicas que a indústria posteriormente emprega para uma variedade de outros propósitos (NELSON, 1990). As atividades de pesquisa acadêmicas estimulam e aumentam o poder das atividades de pesquisa e desenvolvimento (P\&D) realizadas na indústria e criam novos instrumentos e técnicas científicas (ROSENBERG; NELSON, 1994; ROSENBERG, 1992). As universidades formam e treinam engenheiros e cientistas capazes de lidar com problemas associados ao processo inovativo nas empresas (KLEVORICK et al., 1995). 
A partir dos anos 1980, as interaçōes entre universidade e empresas intensificaram-se com o aumento do fluxo de conhecimento, sendo desenvolvidos diversos novos mecanismos institucionais de transmissão de tecnologia, tais como parques tecnológicos ao redor de universidades, escritórios de transferência nas universidades e institutos de pesquisas híbridos coordenados por universidades e empresas (SCHIMANK, 1988, p. 330). Paralelamente, os fenômenos do Vale do Silício e da Estrada 129 nos EUA e de Cambridge na Inglaterra reforçaram a contribuição das universidades no desenvolvimento local por meio da criação de empresas de alta tecnologia em regiôes próximas (VARGA, 1997). Este interesse na contribuição das universidades para o desenvolvimento tecnológico e, consequentemente, crescimento econômico ressurge, pois, como objetivo de política econômica em vários países (WEBSTER, 1994).

Este novo papel e comprometimento acadêmico com o desenvolvimento local e regional modelou um novo contrato social entre as universidades e a sociedade, sendo que o financiamento público destinado a elas é condicionado à sua contribuição direta para a economia (BRISOLLA et al., 1997, p. 188). As universidades deixam de ser "torres de marfim" voltadas à produção de conhecimento para seu próprio uso, passando a constituírem instrumentos de uma economia baseada no conhecimento para promover desenvolvimento e mudança.

Entre as razões atribuídas à aproximação das universidades com o setor produtivo, identificam-se, por parte das empresas (MOWERY; SAMPAT, 2005): custo crescente da pesquisa associada ao desenvolvimento de produtos e serviços necessários para assegurar posiçôes vantajosas num mercado cada vez mais competitivo; necessidade de compartilhar o custo e o risco das pesquisas pré-competitivas com outras instituições que dispõem de suporte financeiro governamental; elevado ritmo de introdução de inovaçôes no setor produtivo e redução do intervalo de tempo que decorre entre a obtenção dos primeiros resultados de pesquisa e sua aplicação; e decréscimo dos recursos governamentais para pesquisa em setores antes profundamente fomentados, como os relacionados ao complexo industrial militar.

Do lado da universidade, as motivações principais seriam: dificuldade crescente para obtenção de recursos públicos para a pesquisa universitária; e interesse da comunidade acadêmica em legitimar seu trabalho junto à sociedade que é, em grande medida, a responsável pela manutenção das instituições universitárias.

Para o Brasil e países da América Latina, uma literatura datada atribuía a fraca interação universidade-empresa (U-E) à ausência de demanda por parte das empresas (BALÁZ; PLONSKI, 1994), que não tinham como estratégias a geração interna 
de conhecimento e a inovação, remetendo às universidades um papel isolado na geração de conhecimento (AROCENA; SUTZ, 2003). Neste contexto, as atividades de colaboração das universidades mais frequentes ocorriam com empresas estatais, pertencentes a setores tecnologicamente mais avançados, e com algumas empresas privadas do setor agroexportador. Em termos da complexidade do seu papel desempenhado na periferia, as universidades, em vez de produtoras de conhecimento, seriam apenas praticantes do conhecimento de fronteira existente. Desta maneira, elas definiam um perfil muito mais de consultoria do que de pesquisa em relação à indústria (AROCENA; SUTZ, 2003).

De acordo com estudos, ainda que estejam presentes interaçôes de menor complexidade e voltadas para a rotina de produção da empresa, como testes e auxílio no controle da qualidade, há também interaçôes mais complexas que envolvem fluxo bidirecional de conhecimento, como é o caso dos projetos cooperados de P\&D (FERNANDES et al., 2010; SUZIGAN et.al., 2009). Por sua vez, a contribuição "indireta" das universidades na formação de pessoal foi apontada como um importante canal para a troca de conhecimento e de informação. Outros trabalhos ainda afirmam que o papel das universidades para o sistema de inovação brasileiro é subestimado (SUZIGAN; ALBUQUERQUE, 2011), pois, contrariamente ao conhecimento convencional, é possível encontrar exemplos históricos virtuosos e de sucesso a respeito da interação entre universidades/IPPs e empresas, resultantes de um processo de construção institucional de longo prazo. Um exemplo é o setor aeroespacial, com a Embraer que se beneficiou da proximidade com o Instituto Tecnológico Aeroespacial (ITA).

Apesar das relevantes contribuições das universidades para o processo de inovação nas empresas, há poucas evidências empíricas sobre o financiamento dos processos cooperativos entre empresas e universidades/IPPs no Brasil. Buscando avançar nesta temática, o objetivo deste artigo é investigar as empresas que financiaram com recursos próprios os projetos em colaboração com universidades/IPPs, na busca de inferir especificidades ou não da interação, em comparação ao conjunto das empresas que financiaram projetos cooperativos com uma composição de recursos próprios e públicos. Para cumprir com tal propósito, utilizou-se a base de dados do BR Survey, com respostas de 319 empresas em 2009, que apresentavam interação com grupos de pesquisa de acordo com o Censo 2004 do Diretório dos Grupos de Pesquisa no Brasil do Conselho Nacional de Desenvolvimento Científico e Tecnológico (DGP/CNPq). 
O texto está organizado em seis seções, além desta introdução. A segunda seção traz uma breve revisão da literatura sobre o financiamento da inovação e da interação universidade-empresa. Procurando caracterizar o processo de inovação realizado pelas empresas industriais brasileiras, a terceira seção apresenta, a partir dos dados da edição 2008 da Pesquisa de Inovação Tecnológica (Pintec/IBGE), as características das empresas inovadoras, os dispêndios em inovação e o financiamento das atividades inovativas no país. A metodologia, exposta na quarta seção, explica a pesquisa que originou o BR Survey do qual foram extraídos os dados utilizados. A quinta seção analisa os resultados do survey para as 135 empresas que financiaram com 100\% de recursos próprios os projetos em colaboração com universidades/ IPPs e para as 94 que financiaram estes mesmos projetos com uma composição de recursos privados e públicos. Finalmente, na última seção, são feitas as considerações finais acerca do trabalho.

\section{Financiamento da inovação e da interação universidade-empresa}

\subsection{Financiamento da inovação}

Conforme destacado por Arrow (1962), os processos de invenção e de pesquisa são caracterizados pela produção de informação e envolvem risco, no sentido de que os resultados não podem ser previstos perfeitamente a partir dos insumos. Em vista disto, para o autor, se a empresa considera um projeto que possui risco e a mesma é incapaz de mudar algo desse risco, então ela teria menor propensão a arcar com este investimento, comparativamente a um investimento seguro, principalmente por ter dificuldade em apropriar-se de todo o retorno de seus esforços de P\&D. Desta forma, há um problema claro de subalocação de recursos para atividades desta natureza. Para atividades de pesquisa básica, este subinvestimento seria ainda maior. Arrow conclui que, para uma alocação ótima de recursos para a invenção e a pesquisa, seria necessário que o governo ou uma instituição não governamental financiasse estes tipos de atividade.

Freeman e Soete (1997) descrevem os diversos tipos de incerteza envolvidos no processo inovativo: a incerteza técnica; a incerteza de mercado; e a incerteza geral da economia (que pode em alguns casos ser descrita como a incerteza do negócio). As incertezas técnica e de mercado são específicas ao projeto de inovação e não podem ser descontadas, eliminadas ou consideradas com um tipo de risco que seja 
segurável. A incerteza do negócio, por sua vez, está presente em todos os investimentos que envolvem resultados futuros. No processo de inovação esta incerteza adquire especial importância, tendo em vista que os investimentos requerem um longo período de maturação.

Mesmo para as inovações com níveis de incerteza mais baixos, os autores destacam que apenas uma pequena proporção da atividade de P\&D é financiada diretamente pelo mercado de capitais. O financiamento do processo inovativo é realizado, primordialmente, por meio da reinversão de lucros da própria empresa. Os autores ainda reforçam que, em vista da incerteza presente no processo de inovação, a maioria das empresas não possui incentivos para empreender inovações radicais, concentrando seus esforços de P\&D em inovaçôes defensivas ou imitativas, na diferenciação de produto e em inovação de processo.

Os investimentos em atividades inovativas ainda são caracterizados por uma perspectiva temporal indefinida, pela dificuldade de apropriação privada dos benefícios (FRENKEL, 1993) e pela indivisibilidade, além de apresentarem uma elevada assimetria de informação entre o ofertante de crédito e o demandante (CHRISTENSEN, 1992). Estas características, que tornam impossíveis quantificações ex-ante dos custos e da lucratividade potencial, dificultam o financiamento externo (ARROW, 1962) e fazem com que os mecanismos de mercados falhem em assegurar um financiamento (funding) adequado (GUINET, 1995).

Outra questão importante no que concerne ao financiamento da inovação é a apropriabilidade dos resultados dos investimentos em P\&D e em inovação. Baixa apropriabilidade dos resultados da P\&D reduz os incentivos privados para investir neste tipo de atividade. Desta forma, nos investimentos em P\&D cujos resultados beneficiam somente a empresa, esta tem incentivos para investir recursos próprios. A P\&D cujos resultados apresentam elevados efeitos de transbordamento (spill-overs) deve ser estimulada com recursos públicos, podendo ser por meio do envolvimento direto dos institutos públicos de $\mathrm{P} \& \mathrm{D}$ nos projetos ou pelo suporte público à atividade de inovação privada (GUSSONI; MANGANI, 2010).

\subsection{Financiamento da interação universidade-empresa}

Dentro da perspectiva de incentivar e favorecer o acesso a técnicas e conhecimentos, por um lado, e de reduzir custo e risco inerentes ao processo de inovação, por outro, é que a interação universidade-empresa vem sendo estimulada como objeto de política em vários países. Para isto, diversas vêm sendo as iniciativas de fomento 
dos governos, podendo-se destacar: criação de programas específicos de fomento à parceria; concessão de fundos (recursos não reembolsáveis) para projetos em parceria; indiretamente por meio da concessão de incentivos fiscais que vinculam a cooperação com universidades/IPPs.

No Brasil, alguns instrumentos de política de ciência, tecnologia e inovação (C\&T\&I) para estímulo à inovação nas empresas têm procurado construir uma ponte entre a indústria e a base de C\&T. Entre eles, destaca-se o financiamento não reembolsável oriundo dos Fundos Setoriais de Ciência e Tecnologia, administrados pela Financiadora de Estudos e Projetos (Finep), para apoio a projetos de C\&T\&I apresentados por instituições científicas e tecnológicas (ICTs) nacionais, que objetivam a geração de conhecimento e sua transferência para empresas de setores considerados estratégicos para o país. ${ }^{1}$ Outra iniciativa em nível federal é a do CNPq, com a criação, em 2008, do programa "RHAE Pesquisador na Empresa", que tem como objetivo estimular a entrada, nas micro, pequenas e médias empresas, de pesquisadores mestres e doutores para atividades de pesquisa, desenvolvimento e inovação (P,D\&I).

Esforços também vêm sendo realizados pelas fundações estaduais de amparo à pesquisa (FAPs) para intensificar o relacionamento entre universidades/IPPs e empresas, dos quais destaca-se a iniciativa da Fapesp, com o Programa Pite (Apoio à Pesquisa em Parceria para Inovação Tecnológica) que financia projetos de pesquisa em instituiçôes acadêmicas ou institutos de pesquisa, desenvolvidos em cooperação com pesquisadores de empresas. Algumas FAPs, por meio da Finep, implantaram o Programa de Apoio à Pesquisa em Empresas (Pappe), com objetivo de promover o desenvolvimento tecnológico das empresas, induzindo-as à aproximação com instituições de ensino e pesquisa.

Alguns trabalhos recentes vêm buscando avaliar a política de C\&T\&I voltada à cooperação universidade-empresa no país. Calzolaio e Dathein (2012) avaliaram os impactos da Lei 11.196/05 (Lei do Bem) sobre as atividades inovativas das empresas usuárias deste incentivo fiscal e constataram que se trata de um instrumento adequado para intensificar no curto prazo as atividades de inovação das empresas que já inovam, embora não seja apropriado para ampliar o número de empresas inovadoras e para apoiar projetos arriscados, que necessitam de grande aporte de capital e comprometem os custos de longo prazo. Os autores identificaram, com base nos dados da Pintec para as empresas usuárias da Lei do Bem, um aumento

1 Os recursos dos Fundos Setoriais, em geral, são aplicados em projetos selecionados por meio de chamadas públicas. 
significativo do número daquelas que atribuíram alto grau de importância à cooperação com universidades e IPPs para a inovação: uma variação de $70,4 \%$ entre as pesquisas de 2005 e 2008 e de $312,5 \%$ entre as de 2000 e 2008. Ademais, o número de empresas que negligenciavam a importância da cooperação com universidades e institutos de pesquisa diminuiu intensamente após a Lei do Bem $(48,1 \%$ entre a Pintec 2005 e a 2008). Adicionalmente, verificou-se que, depois da Lei do Bem, os gastos com P\&D interno e a aquisição de P\&D externo cresceram, respectivamente, $77,2 \%$ e $81,2 \%$ no conjunto das empresas usuárias do benefício fiscal.

Com relação aos Fundos Setoriais (projetos de subvenção nacionais e projetos cooperativos), administrados pela Finep, De Negri et al. (2010) identificaram que, no período 2000-2008, as políticas acertaram o alvo ao selecionar empresas mais capacitadas tecnologicamente. Já quanto às características dos projetos financiados pelos Fundos, os autores verificaram que, de modo geral, aqueles em que as participaçôes de empresas são maiores em termos de valor envolvem também um número maior de pesquisadores. Os autores constataram ainda que, entre as mais de 1.300 empresas industriais que estabeleceram parcerias com grupos de pesquisa brasileiros, apenas 194 foram apoiadas pelos Fundos Setoriais.

Da mesma forma, Morais (2010), ao analisar as características inovadoras das empresas beneficiadas pelos programas cooperativos da Finep, observou que os referidos programas representam uma fonte importante de recursos para projetos de inovação com maior densidade tecnológica e para empresas de maior porte. $\mathrm{O}$ autor concluiu que, pela maior especificidade das inovaçôes associadas às chamadas cooperativas, "pode-se considerar que os projetos cooperativos constituem uma agenda vertical de P\&D, acessíveis a número limitado de ICTs e de empresas capacitadas para o seu desenvolvimento" (MORAIS, 2010, p. 18).

Salles Filho (2011) apresenta resultados recentes de avaliação dos impactos dos programas da Fapesp Pesquisa Inovativa em Pequenas Empresas (Pipe) ${ }^{2}$ e Pite. A avaliação do Pite demonstrou que o programa estimulou novas parcerias entre empresas e ICTs (cerca de 75\% das empresas envolvidas passaram a se relacionar de forma mais intensa e frequente com ICTs). Além disso, $40 \%$ das empresas que não tinham como rotina estabelecer contato com ICTs passaram a fazê-lo como decorrência do programa. Por outro lado, o autor observou que o Pite e seus projetos pouco alavancaram a inovação junto às empresas e que as tecnologias resultantes

2 Aporta recursos para projetos de pesquisa desenvolvidos por pesquisadores que tenham vínculo empregatício com pequenas empresas ou que estejam associados a elas para sua realização. 
dos projetos em parceria foram pouco incorporadas pelas empresas. Houve, pois, aumento do interesse por pesquisa, mas quase sempre executada nas ICTs e com baixo impacto junto ao core business das empresas envolvidas na interação.

Estudos empíricos realizados por Araujo (2007) e Paranhos (2010) também identificaram que a possibilidade de financiamento governamental constitui uma importante motivação para a interação de empresas com universidades e IPPs, funcionando como um catalisador desse processo de aproximação entre as instituiçôes. O estudo de caso comparativo de quatro processos de colaboração em P\&D entre empresas e universidades/IPP no Brasil, realizado por Araujo (2007), permite inferir que os recursos públicos para a promoção da cooperação entre a indústria e a academia foram decisivos para a formação de parcerias que envolveram desenvolvimentos conjuntos altamente inovadores. Por outro lado, a autora constatou que as empresas arcaram com o financiamento integral dos projetos de P\&D nas parcerias com universidades/IPP voltadas para o desenvolvimento conjunto de processo e produto que podem ser caracterizados por inovações incrementais, adaptadas às necessidades das empresas, e já adotadas em outros países.

A partir de informações sobre a remuneração da interação universidade-empresa, declarada pelos líderes dos grupos de pesquisa do CNPq (Censo 2008), Rapini e Oliveira (2012) demonstraram que as remuneraçóes mais frequentes foram, por um lado, a transferência de recursos financeiros e materiais entre as partes e, por outro, as remuneraçōes vinculadas à geração de conhecimento tácito, como bolsas e troca de pessoal. Além disso, os recursos financeiros do parceiro foram utilizados para remunerar, principalmente, pesquisas científicas de curto prazo, tecnologia e software desenvolvidos pelo grupo de pesquisa e atividades de consultoria, atividades de menor risco e que têm retorno imediato. Por sua vez, as parcerias entre grupos de pesquisa e empresas envolvendo risco foram utilizadas para remunerar atividades de pesquisa sem uso imediato de resultados (ou de longo prazo), desenvolvimento de tecnologia pelo setor produtivo e treinamento de pessoal do grupo.

\section{0 financiamento à inovação: evidências da Pintec 2008}

A fim de caracterizar o financiamento à inovação no Brasil, esta seção apresenta, de forma breve, evidências da Pintec 2008. Esta pesquisa, realizada pelo IBGE, contém dados referentes às estratégias inovativas das empresas industriais brasileiras. As informaçōes relevantes para o presente trabalho são distribuídas nas três subseções a seguir. 


\subsection{Caracterização geral das empresas inovadoras}

$\mathrm{Na}$ Pintec 2008, das 106.862 empresas industriais brasileiras com dez ou mais pessoas ocupadas, 41.262 realizaram algum tipo de inovação, representando uma taxa de inovação de $38,6 \%$. A maioria das empresas inovadoras é de pequeno porte (88,1\%), tendo até 49 empregados $(73,7 \%)$.

No geral, as empresas inovaram mais em processo (na média 32,0\%) do que em produto (na média 23,7\%), conforme pode ser visualizado na Tabela 1. À medida que o tamanho da empresa aumenta, cresce também a taxa de inovação em produto e em processo, sendo as grandes empresas aquelas com maiores taxas de inovação $(71,7 \%)$. Se observado o grau de novidade do produto, o desempenho das grandes empresas foi ainda maior comparativamente às demais empresas, que apresentaram baixo desempenho em termos tanto de produtos novos para o mercado mundial como de processos novos para o setor no Brasil. A estratégia de inovação adotada pela maioria das empresas pode ser caracterizada como defensiva, de acordo com a taxonomia de Freman e Soete (1997).

TABELA 1

Empresas industriais brasileiras inovadoras e taxa de inovação, segundo faixa de pessoal ocupado Brasil - 2008

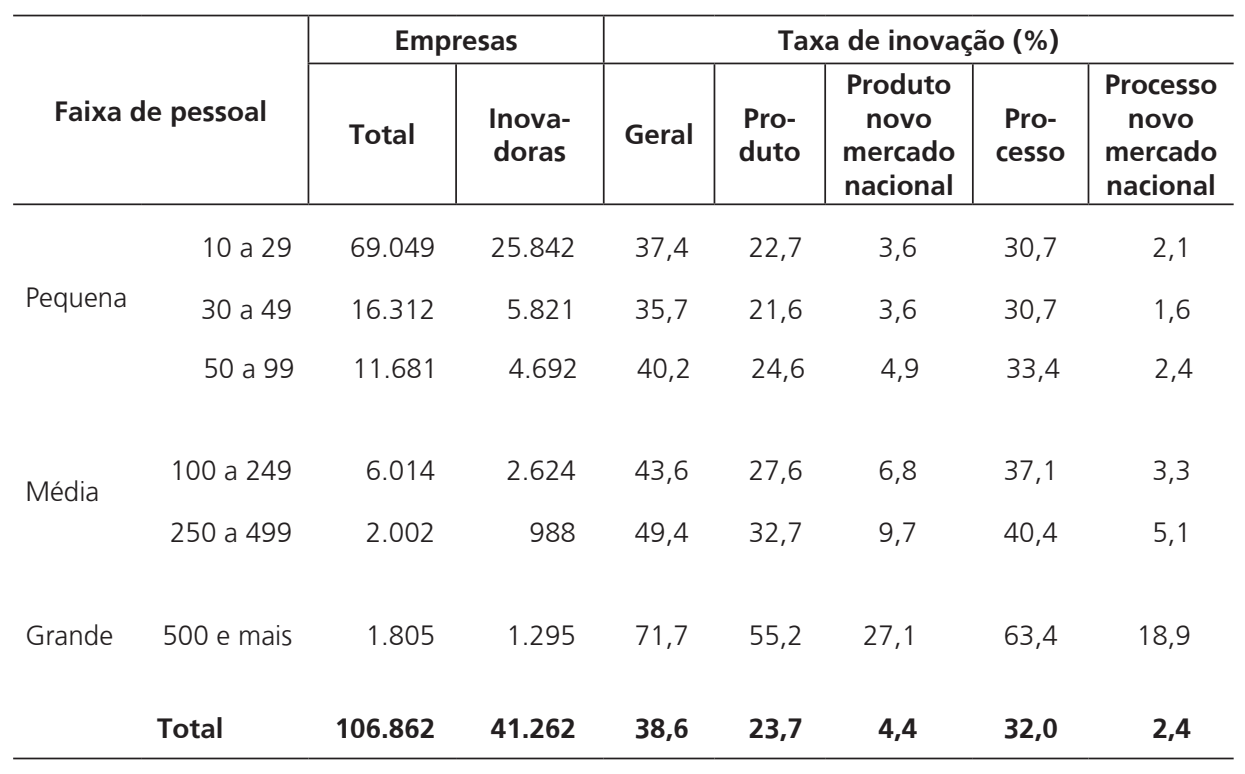

Fonte: IBGE. Pesquisa de Inovação Tecnológica - Pintec 2008. Elaboração dos autores. 


\subsection{Dispêndios em inovação e fontes de financiamento}

Tem-se que 21.966 empresas, ou 66,9\% das que inovaram entre 2006 e 2008, tiveram dispêndios com atividades inovativas em 2008. A Tabela 2 apresenta o percentual dos gastos em atividades internas de $\mathrm{P} \& \mathrm{D}$, na aquisição de máquinas e equipamentos e nas demais atividades sobre o total de dispêndio nas atividades inovativas, segundo o número de empregados das empresas. Na média, as empresas despenderam cerca de $28,1 \%$ dos recursos em atividades internas de P\&D e cerca de $44,9 \%$ na aquisição de máquinas e equipamentos. O percentual mais elevado de gastos em P\&D interno correspondeu às grandes e médias empresas, refletindo maior capacidade destas empresas de investirem seus lucros acumulados em atividades de maiores risco e incerteza.

Por sua vez, as pequenas empresas tiveram parte considerável dos gastos com atividades inovativas voltados para a aquisição de máquinas e equipamentos e para outras atividades inovativas que abrangem treinamentos, aquisição de software, projeto industrial e atividades de comercialização. A Tabela 2 também apresenta duas atividades de inovação que podem estar vinculadas à interação com universidades/IPP: aquisição externa de P\&D e de outros conhecimentos. A primeira foi mais frequente nas médias ( 250 a 499 ocupados) e grandes empresas, o que pode estar refletindo a necessidade da existência de capacidade interna para absorver a P\&D gerada fora da empresa. Por sua vez, a aquisição externa de conhecimento, menos complexa que a P\&D, foi utilizada por empresas de diferentes portes. Mas estas duas atividades representam pouco dos dispêndios em atividades inovativas, totalizando, juntas, 7,5\%.

A Tabela 3 apresenta a estrutura de financiamento das atividades de P\&D e de inovação de acordo com o tamanho da empresa. No geral, as empresas inovadoras brasileiras financiam parte considerável de suas atividades inovativas com recursos próprios (na média 75,0\%), o que corrobora o postulado na literatura sobre autofinanciamento dos investimentos em $\mathrm{P} \& \mathrm{D}$. As pequenas (de 30 a 49 empregados) e médias empresas (de 250 a 499) foram as que registraram a maior parcela de recursos de terceiros no financiamento às atividades de $\mathrm{P} \& \mathrm{D}$, ainda que de fontes predominantes diferentes: nas pequenas, 34,0\% dos recursos foram públicos e, nas médias, $45,0 \%$ foram privados. Este aporte considerável de recursos privados nas médias empresas pode ser proveniente de capital de risco.

As outras atividades de inovação também foram financiadas na sua maioria (na media 75,0\%) com recursos próprios. Assim como no caso da $\mathrm{P} \& \mathrm{D}$, a maior 
parcela de recursos públicos $(24,0 \%)$ foi para as empresas de pequeno porte (30 a 49). Provavelmente, tais recursos sejam, em sua maioria, utilizados para a aquisição de máquinas e equipamentos, principal dispêndio nas atividades de inovação (Tabela 2), que se constituem em si mesmos garantias para financiamentos.

TABELA 2

Distribuição dos dispêndios em atividades de inovação das empresas industriais brasileiras, por tipo de atividade, segundo faixa de pessoal ocupado

Brasil - 2008

\begin{tabular}{cc|c|c|c|c|c|}
\hline \multicolumn{2}{c}{$\begin{array}{c}\text { Faixa de pessoal } \\
\text { ocupado }\end{array}$} & $\begin{array}{c}\text { P\&D } \\
\text { interno }\end{array}$ & $\begin{array}{c}\text { Máquinas } \\
\text { e equipa- } \\
\text { mentos }\end{array}$ & $\begin{array}{c}\text { Aquisição } \\
\text { externa de } \\
\text { P\&D }\end{array}$ & $\begin{array}{c}\text { Aquisição } \\
\text { de outros } \\
\text { conhecimen- } \\
\text { tos externos }\end{array}$ & $\begin{array}{c}\text { Demais } \\
\text { atividades }\end{array}$ \\
\hline \multirow{2}{*}{ Pequena } & 10 a 29 & 8,9 & 61,7 & 1,0 & 2,8 & 25,5 \\
& 30 a 49 & 9,7 & 70,4 & 0,4 & 3,1 & 16,4 \\
Média & 50 a 99 & 9,8 & 66,9 & 0,7 & 3,0 & 19,7 \\
\multirow{4}{*}{ Grande } & 100 a 249 & 15,2 & 54,9 & 0,9 & 2,1 & 26,9 \\
& 250 a 499 & 10,4 & 57,3 & 7,6 & 6,7 & 18,0 \\
& 500 e mais & 36,9 & 36,9 & 5,0 & 2,6 & 18,5 \\
\hline
\end{tabular}

Fonte: IBGE. Pesquisa de Inovação Tecnológica - Pintec 2008. Elaboração dos autores.

TABELA 3

Distribuição das fontes de financiamento das atividades de inovação das empresas industriais brasileiras, por tipo de atividade, segundo faixa de pessoal ocupado Brasil - 2008

Em porcentagem

\begin{tabular}{|c|c|c|c|c|c|c|c|c|c|}
\hline \multirow{4}{*}{\multicolumn{2}{|c|}{$\begin{array}{l}\text { Faixas de pessoal } \\
\text { ocupado }\end{array}$}} & \multicolumn{8}{|c|}{ Estrutura do financiamento } \\
\hline & & \multicolumn{4}{|c|}{ Das atividades de P\&D } & \multicolumn{4}{|c|}{ Outras atividades de inovação } \\
\hline & & \multirow{2}{*}{ Próprias } & \multicolumn{3}{|c|}{ De terceiros } & \multirow{2}{*}{ Próprias } & \multicolumn{3}{|c|}{ De terceiros } \\
\hline & & & Total & Privado & Público & & Total & Privado & Público \\
\hline \multirow{3}{*}{ Pequena } & 10 a 29 & 82,0 & 18,0 & 7,0 & 12,0 & 72,0 & 28,0 & 9,0 & 19,0 \\
\hline & 30 a 49 & 56,0 & 44,0 & 10,0 & 34,0 & 50,0 & 50,0 & 26,0 & 24,0 \\
\hline & 50 a 99 & 85,0 & 15,0 & 8,0 & 7,0 & 71,0 & 29,0 & 12,0 & 17,0 \\
\hline \multirow{2}{*}{ Média } & 100 a 249 & 73,0 & 27,0 & 4,0 & 22,0 & 75,0 & 25,0 & 7,0 & 17,0 \\
\hline & 250 a 499 & 50,0 & 50,0 & 45,0 & 5,0 & 61,0 & 39,0 & 23,0 & 15,0 \\
\hline Grande & 500 e mais & 78,0 & 22,0 & 1,0 & 21,0 & 81,0 & 19,0 & 3,0 & 16,0 \\
\hline Total & & 76,0 & 24,0 & 4,0 & 19,0 & 75,0 & 25,0 & 9,0 & 16,0 \\
\hline
\end{tabular}

Fonte: IBGE. Pesquisa de Inovação Tecnológica - Pintec 2008. Elaboração dos autores. 


\subsection{Apoio do governo}

A Tabela 4 sumariza as empresas que receberam apoio do governo de acordo com o tamanho. Em 2008, 9.214 empresas (22,3\% das que implementaram inovação) receberam algum tipo de apoio do governo. Deste conjunto, $1.240(13,4 \%)$ receberam incentivos fiscais (5,3\% para atividades de P\&D e 8,1\% da Lei de Informática), $311(3,4 \%)$ foram contempladas com a subvenção econômica e 6.906 (75,0\%) receberam algum tipo de financiamento (sendo $60,3 \%$ para compra de máquinas e equipamentos, $6,3 \%$ para projetos de $\mathrm{P} \& \mathrm{D}$ e $4,2 \%$ para projetos de $\mathrm{P} \& \mathrm{D}$ em cooperação com universidades). Cerca de $1 / 3$ das empresas recebeu outros tipos de apoio, que abrangem bolsas RHAE/CNPq oferecidas a pesquisadores nas empresas, aporte de capital de risco e outros programas.

As pequenas e médias empresas, em conjunto, receberam $56,9 \%$ dos incentivos fiscais às atividades de P\&D e 93,8\% dos incentivos fiscais da Lei de Informática. As pequenas e grandes empresas foram responsáveis, respectivamente, por $68,4 \%$ e $16,2 \%$ do financiamento a projetos em cooperação com universidades/IPPs. As pequenas empresas foram as principais beneficiárias do financiamento a projetos de P\&D e inovação tecnológica ( $80,9 \%$ do total das empresas) e à compra de máquinas e equipamentos $(88,2 \%)$ e dos outros programas de apoio $(86,0 \%)$.

Assim, os dados da Tabela 4 indicam que os recursos públicos são utilizados no Brasil, em sua maioria, para aquisição de máquinas e equipamentos. Adicionalmente, verifica-se que o financiamento público para projetos em parceria entre empresas inovadoras e universidades/IPPs representa pouco em termos do montante de recursos do governo, contemplando, ademais, um reduzido número de empresas inovadoras.

Os dados da Pintec 2008, analisados nesta seção, permitem identificar que, de modo geral, as empresas brasileiras inovam mais em processo do que em produto. Adicionalmente, há um predomínio de inovaçōes voltadas para as próprias empresas, sendo pouco expressivas as inovaçóes de produtos e processos de empresas brasileiras orientadas para o mercado. Por outro lado, a aquisição de máquinas e equipamentos constitui a atividade mais importante na estrutura dos dispêndios realizados com inovações pelas empresas brasileiras, reforçando este quadro. Em contraposição, são bem menos significativos os gastos realizados com P\&D interno (e também com aquisição externa de $\mathrm{P} \& D$ ), caracterizando um padrão de inovação calcado no acesso ao conhecimento tecnológico por meio da incorporação de máquinas e equipamentos e, portanto, de esforços de atualização e modernização. 
TABELA 4

Empresas industriais brasileiras que implementaram inovação e receberam apoio do governo, segundo porte das empresas

Brasil - 2008

\begin{tabular}{|c|c|c|c|c|c|c|c|c|c|}
\hline \multirow{4}{*}{$\begin{array}{c}\text { Porte } \\
\text { das } \\
\text { empresas }\end{array}$} & \multicolumn{9}{|c|}{ Empresas que implementaram inovações } \\
\hline & \multirow[b]{3}{*}{ Total } & \multicolumn{8}{|c|}{ Receberam apoio do governo, por tipo de programa } \\
\hline & & \multirow[b]{2}{*}{ Total } & \multicolumn{3}{|c|}{ Incentivo fiscal } & \multicolumn{3}{|c|}{ Financiamento } & \multirow[b]{2}{*}{$\begin{array}{c}\text { Outros } \\
\text { progra- } \\
\text { mas de } \\
\text { apoio }\end{array}$} \\
\hline & & & $\begin{array}{l}\text { P\&D } \\
\text { (1) }\end{array}$ & $\begin{array}{l}\text { Lei da } \\
\text { Infor- } \\
\text { mática } \\
(2)\end{array}$ & $\begin{array}{l}\text { Subven- } \\
\text { ção eco- } \\
\text { nômica }\end{array}$ & $\begin{array}{l}\text { P\&D em } \\
\text { parceria } \\
\text { com } \\
\text { univers. }\end{array}$ & P\&D & $\begin{array}{c}\text { Compra } \\
\text { de maq. } \\
\text { equip. }\end{array}$ & \\
\hline $\begin{array}{l}\text { Total } \\
\text { (n.abs.) }\end{array}$ & 41.262 & 9.214 & 492 & 748 & 311 & 383 & 581 & 5.559 & 2.981 \\
\hline Total (\%) & & 100,0 & 5,3 & 8,1 & 3,4 & 4,2 & 6,3 & 60,3 & 32,4 \\
\hline Pequenas & 36.555 & 7.866 & 198 & 631 & 209 & 262 & 470 & 4901 & 2.563 \\
\hline Médias & 3.612 & 875 & 82 & 71 & 43 & 58 & 44 & 510 & 296 \\
\hline Grandes & 1.295 & 473 & 212 & 46 & 59 & 62 & 67 & 148 & 122 \\
\hline
\end{tabular}

Fonte: IBGE. Pesquisa de Inovação Tecnológica - Pintec 2008. Elaboração dos autores.

(1) Incentivo fiscal à P\&D (Leis n. 8.661 e 10.332).

(2) Incentivo fiscal da Lei da Informática (Leis n. 10.176, 10.664 e 11.077).

Os dados da Pintec 2008 também demonstram que, de modo geral, as empresas inovadoras brasileiras financiam parte considerável de suas atividades inovativas com recursos próprios. Estes, por sua vez, são destinados a atividades inovativas que envolvem menores custos e risco, conforme apontado no parágrafo anterior. Já o financiamento público é utilizado, em sua maioria, para a aquisição de máquinas e equipamentos, sendo poucos os recursos (públicos) direcionados ao financiamento das parcerias entre empresas e universidades e IPPs.

Assim, os dados da Pintec já sinalizam para os resultados do BR Survey que serão apresentados na $5^{\text {a }}$ seção: a maioria da cooperação entre empresas inovadoras e universidades/IPPs, relacionada à geração de conhecimento e de inovação, é financiada, no Brasil, com recursos das próprias empresas.

Além disso, 92,4\% das empresas entrevistadas pelo BR Survey introduziram inovações de produto nos últimos três anos e 94,0\% inovaram em processo. Estes dados sugerem que há uma associação entre interação com a infraestrutura científica nacional e inovação nas empresas pesquisadas, ou seja, que as empresas que possuem projetos conjuntos com universidades/IPPs, no geral, são inovadoras. 


\section{Metodologia do BR Survey}

Este artigo apresenta resultados de uma pesquisa realizada com empresas e universidades/IPPs no Brasil, doravante denominada BR Survey. Foi enviado um questionário a cada uma das 1.622 empresas industriais localizadas no Brasil que interagiam com os grupos de pesquisa, de acordo com o Censo de 2004 do DGP/CNPq. ${ }^{3}$

A aplicação do questionário ocorreu entre 13 de abril e 30 de novembro de 2009, tendo como resultado 319 questionários respondidos, representando 18,9\% do total dos questionários enviados. Estes foram respondidos, preferencialmente, pelos responsáveis pelas atividades de $\mathrm{P} \& \mathrm{D}$ e/ou pelas interações com universidades/ IPPs nas empresas, por meio de uma plataforma on line. As respostas relativas às questões se basearam na realidade da época em que foi aplicado o questionário às empresas, sendo inclusive o questionário definido internacionalmente. ${ }^{4}$

O Censo 2004 serviu como fonte para identificar as empresas que interagiram com os grupos de pesquisa no referido ano. Este procedimento foi adotado em vista de limitações e restriçõos de tempo e da dificuldade de levantar informações sobre empresas brasileiras e também de obter dados das mesmas. Trabalhos anteriores apontaram, inclusive, para uma subestimação das interações declaradas pelos líderes dos grupos de pesquisa (RAPINI et al., 2009). Mesmo com estas limitações, as informações coletadas na pesquisa são inéditas, justificando sua análise e o esforço de publicação.

O questionário enviado às empresas é composto por 22 questões, distribuídas em cinco blocos. $\mathrm{O}$ primeiro contempla seis questôes relativas às atividades inovativas e de P\&D da empresa. O segundo possui sete questôes a respeito das fontes de informação e conhecimento e/ou modos de interação nas quais a empresa se baseou para realizar seus projetos de inovação. $\mathrm{O}$ terceiro bloco, compreendido por apenas uma questão, refere-se à importância dada pelas empresas para a contribuição das universidades/IPPs para suas atividades de pesquisa, de acordo com as áreas de conhecimento. O quarto, por sua vez, investiga de forma mais aprofundada a colaboração da empresa com universidades/IPPs abrangendo seis questôes sendo: razōes para a colaboração; iniciativa para estabelecer a colaboração; sucesso ou não da colaboração; obstáculos à colaboração; tempo de colaboração; e fonte de financiamento das atividades colaborativas. Finalmente, o quinto bloco compreende apenas

3 No DGP a interação com o setor produtivo é obtida por meio da resposta do líder do grupo de pesquisa.

4 Sobre detalhes do projeto RoKS, ver Fernandes et al. (2010). 
duas questóes, relativas às funções atribuídas à universidade por parte da empresa. Neste artigo serão alisadas as respostas referentes às fontes de informação utilizadas, aos modos de interação e às razões para a colaboração, na busca de inferir ou não especificidades oriundas da natureza da fonte de financiamento.

O questionário não define a priori o que seria colaboração com universidades/ IPPs, mas apresenta um conjunto amplo de opçôes paras as empresas nas questōes que investigam esta temática. Durante o processo de elaboração do questionário, dois foram os pilares que o nortearam. Primeiro, manter um mínimo de comparabilidade com pesquisas semelhantes realizadas nos outros países, bem como com a pesquisa original norte-americana Carnegie Mellon Survey (COHEN et al., 2002). Segundo, inserir especificidades do processo de cooperação das empresas de forma a avançar na compreensão da realidade brasileira. Em vista disto, foram contempladas dentro de "colaboração" atividades intensivas em conhecimento (como pesquisas e projetos de $\mathrm{P} \& \mathrm{D}$ ), bem como atividades simples e pontuais ou pouco complexas (como testes, controle da qualidade, consultorias, etc.).

\section{A natureza do financiamento da interação universidade-empresa no Brasil}

Esta seção apresenta resultados do BR Survey referentes às fontes de informação, aos modos de interação e à motivação para a colaboração pela perspectiva da fonte predominante de financiamento, na tentativa de responder à pergunta inicial do artigo. Para tanto, a mesma é subdividida em duas partes. A primeira expõe as características das empresas que interagiram com os grupos de pesquisa sob a perspectiva da fonte predominante de financiamento. A segunda analisa as respostas do questionário referentes à cooperação universidade-empresa, mencionadas anteriormente, sob a perspectiva da fonte predominante de financiamento.

\subsection{Caracterização das empresas de acordo com fonte de financiamento}

A Tabela 5 apresenta as respostas das empresas em termos da fonte de financiamento dos projetos em colaboração com universidades/IPPs. ${ }^{5}$ Observa-se que estes projetos foram financiados, de forma preponderante, exclusivamente com recursos próprios

5 Como a empresa não possui a opção de explicitar a fonte de financiamento em cada modo de interação, o resultado refere-se à média de financiamento dos projetos de cooperação (conforme explicado na seção 4) com universidades/ IPPS. 
das empresas (44,8\% das empresas entrevistadas). A participação majoritária do financiamento dos processos cooperativos por meio de recursos próprios das empresas também se verificou nos casos em que eles foram financiados com recursos próprios e públicos (participações médias de 58,5\% e 41,5\%, respectivamente).

É notável o fato de que é muito baixa a participação das empresas que financiaram seus projetos em colaboração com universidades/IPPs somente com recursos públicos (5,0\% das empresas pesquisadas). ${ }^{6}$ Adicionalmente, constata-se que nenhuma das empresas pesquisadas financiou seus projetos em colaboração com universidades e IPPs exclusivamente com recursos de terceiros (capital de risco, bancos privados, etc.).

TABELA 5

Empresas brasileiras que responderam ao BR Survey, segundo fontes de financiamento dos projetos em colaboração com as universidades/IPPs 2009

\begin{tabular}{|c|c|c|c|c|c|}
\hline Fontes de financiamento & $\begin{array}{c}\text { Número } \\
\text { de } \\
\text { respostas }\end{array}$ & $\begin{array}{l}\% \\
\text { média }\end{array}$ & $\begin{array}{c}\% \\
\text { máxima }\end{array}$ & $\begin{array}{c}\% \\
\text { mínima }\end{array}$ & $\begin{array}{l}\text { Desvio- } \\
\text { padrão }\end{array}$ \\
\hline Somente recursos próprios & $143(1)$ & 96,0 & 100,0 & 1,0 & 17,8 \\
\hline $\begin{array}{l}\text { Somente recursos públicos } \\
\text { (Finep, CNPq, FAPs, BNDES, etc.) }\end{array}$ & 16 & 83,1 & 100,0 & 15,0 & 31,3 \\
\hline $\begin{array}{l}\text { Somente recursos de terceiros } \\
\text { (capital de risco, bancos } \\
\text { privados, etc.) }\end{array}$ & 0 & 0,0 & 0,0 & 0,0 & 0,0 \\
\hline Recursos próprios e públicos & 94 & $\begin{array}{r}58,5 \text { e } \\
41,5\end{array}$ & $\begin{array}{r}99,0 \text { e } \\
97,0\end{array}$ & 1,0 e 3,0 & 28,6 \\
\hline $\begin{array}{l}\text { Os três tipos (próprios, públicos } \\
\text { e de terceiros) }\end{array}$ & 11 & $\begin{array}{r}41,4 \\
42,3 \mathrm{e} \\
16,4\end{array}$ & $\begin{array}{l}90,0 \\
70,0 \\
40,0\end{array}$ & $\begin{array}{r}20,0 ; 5,0 \\
5,0\end{array}$ & $\begin{array}{r}22,6 \\
21,8 ; 10,5\end{array}$ \\
\hline Sem resposta & 55 & - & & - & - \\
\hline $\begin{array}{l}\text { Total de empresas } \\
\text { entrevistadas }\end{array}$ & 319 & & & & \\
\hline
\end{tabular}

Fonte: BR Survey. Elaboração dos autores.

(1) Número de empresas que declararam utilizar somente recursos próprios, mesmo que menos de $100 \%$ dos recursos.

616 empresas financiaram seus processos colaborativos com universidades/IPPs exclusivamente com recursos públicos, nas seguintes modalidades: financiamento para projetos de P\&D e inovação tecnológica (utilizado por oito empresas); incentivo fiscal à $P \& D$ e inovação tecnológica (Leis n. 8.661, 10.332 e 11.196) (cinco empresas); financiamento para a participação em projetos de P\&D e inovação tecnológica em parceria com universidades/IPPs (cinco empresas); bolsas oferecidas pelas FAPs e RHAE/CNPq para pesquisadores em empresas (cinco empresas). Destaca-se que as empresas poderiam assinalar mais de uma opção. 
A fim de investigar a influência da natureza do financiamento na interação universidade-empresa no Brasil, serão analisados, no restante do artigo, dois conjuntos de empresas que responderam ao BR Survey: as 135 empresas que declararam financiar com $100 \%$ de recursos próprios os projetos colaborativos com universidades/ IPPs; e as 94 que financiaram estes mesmos projetos com composição de recursos privados e públicos.

Em termos do porte, não é possível inferir preponderância do tamanho da empresa que financiou a interação exclusivamente com recursos próprios, estando os três estratos - pequena, média e grande - similarmente representados, com cerca de 1/3 do total. Já entre as empresas que financiaram seus processos cooperativos com universidades/IPPs com recursos próprios e públicos, predominam aquelas de grande porte $(38,3 \%)$, seguidas pelas pequenas empresas $(31,8 \%)$. Em uma perspectiva comparativa entre os dois conjuntos de empresas, tem-se que a participação relativa das de médio porte é maior $(34,9 \%)$ entre aquelas que financiaram a interação com $100 \%$ de recursos próprios, enquanto a participação das grandes empresas é superior $(38,3 \%)$ no conjunto das que utilizaram recursos próprios e públicos no financiamento da cooperação. No caso das grandes empresas, os recursos públicos são, principalmente, os incentivos fiscais e o financiamento destinado à parceria com ICTs. ${ }^{7}$

Um cruzamento das variáveis porte e origem do capital nas empresas pesquisadas pelo BR Survey (Tabela 6) mostra que o financiamento da interação exclusivamente com recursos próprios prevalece em todos os tamanhos de empresa, embora sua participação seja mais relevante no conjunto das pequenas empresas de capital privado nacional $(90,5 \%)$, seguidas pelas grandes empresas nacionais $(60,0 \%)$. Da mesma forma, constata-se que, entre as empresas que financiaram seus processos cooperativos com universidades/IPPs com recursos próprios e públicos, há uma predominância daquelas de pequeno porte privado $(90,0 \%)$, seguidas pelas médias empresas nacionais $(63,2 \%)^{8}$.

$761 \%$ das empresas que utilizaram recursos públicos e privados receberam incentivos fiscais e/ou o financiamento destinado à parceria com ICTs.

8 Entre os principais mecanismos utilizados para financiar a inovação com recursos públicos, estão: financiamento à P\&D para cooperação com universidades/IPPs (utilizado por mais da metade das empresas de todos os portes de capital privado e mais de $3 / 4$ das grandes empresas de capital misto) e incentivos fiscais (utilizados por grandes empresas de capital privado e misto, sendo $66 \%$ e $55 \%$, respectivamente). 
TABELA 6

Distribuição das empresas brasileiras que responderam ao BR Survey e que financiaram projetos de colaboração com universidades/IPPs, por porte da empresa e natureza do

$$
\text { financiamento, segundo origem do capital }
$$

2009

Em porcentagem

\begin{tabular}{|c|c|c|c|c|c|c|c|c|c|}
\hline \multirow{2}{*}{$\begin{array}{l}\text { Origem } \\
\text { do capital }\end{array}$} & \multicolumn{3}{|c|}{ Pequena } & \multicolumn{3}{|c|}{ Média } & \multicolumn{3}{|c|}{ Grande } \\
\hline & $\begin{array}{l}\text { Somente } \\
\text { recursos } \\
\text { próprios }\end{array}$ & $\begin{array}{l}\text { Recursos } \\
\text { próprios e } \\
\text { públicos }\end{array}$ & Total & $\begin{array}{l}\text { Somente } \\
\text { recursos } \\
\text { próprios }\end{array}$ & $\begin{array}{l}\text { Recursos } \\
\text { próprios e } \\
\text { públicos }\end{array}$ & Total & $\begin{array}{l}\text { Somente } \\
\text { recursos } \\
\text { próprios }\end{array}$ & $\begin{array}{l}\text { Recursos } \\
\text { próprios } \\
\text { e públicos }\end{array}$ & Total \\
\hline Privado & 90,5 & 90,0 & 90,3 & 57,4 & 63,2 & 63,5 & 60,0 & 58,3 & 59,3 \\
\hline Público & 2,4 & 3,3 & 2,8 & 2,1 & 5,3 & 1,4 & 6,7 & 11,1 & 8,6 \\
\hline Estrangeiro & 2,4 & 0,0 & 1,4 & 23,4 & 22,8 & 20,3 & 24,4 & 5,6 & 16,0 \\
\hline Misto (1) & 4,8 & 6,7 & 5,6 & 14,9 & 8,8 & 13,5 & 8,9 & 25,0 & 16,0 \\
\hline $\begin{array}{l}\text { Não } \\
\text { declarado }\end{array}$ & 0,0 & 0,0 & 0,0 & 2,1 & 0,0 & 1,4 & 0,0 & 0,0 & 0,0 \\
\hline Total & 100,0 & 100,0 & 100,0 & 100,0 & 100,0 & 100,0 & 100,0 & 100,0 & 100,0 \\
\hline
\end{tabular}

Fonte: BR Survey. Elaboraçăo dos autores

(1) corresponde a duas origens distintas do capital para a mesma empresa, sejam nacional e estrangeiro, sejam público e privado. 
Quanto ao setor de atividade econômica, observa-se, pelos dados da Tabela 7, que, entre as empresas que financiaram a cooperação com universidades/IPPs com $100 \%$ de recursos próprios, há predomínio daquelas pertencentes à indústria de transformação, notadamente dos setores de alimentos, bebida e fumo (15,6\%) e fabricação de produtos químicos $(11,1 \%)$ e de produtos farmoquímicos/farmacêuticos $(9,6 \%)$.

TABELA 7

Distribuição das empresas brasileiras que responderam ao BR Survey e que financiaram projetos de colaboração com universidades/IPPs, por natureza do financiamento, segundo setor de atividade 2009

\begin{tabular}{|c|c|c|c|c|c|c|}
\hline \multirow[t]{2}{*}{ Setor CNAE } & \multicolumn{2}{|c|}{$\begin{array}{l}\text { Somente recursos } \\
\text { próprios }\end{array}$} & \multicolumn{2}{|c|}{$\begin{array}{c}\text { Recursos próprios } \\
\text { e públicos }\end{array}$} & \multicolumn{2}{|c|}{ Total } \\
\hline & N. abs. & $\%$ & N. abs. & $\%$ & N. abs. & $\%$ \\
\hline Agricultura & 1 & 0,7 & 10 & 10,6 & 18 & 5,6 \\
\hline Indústria extrativas & 8 & 5,9 & 2 & 2,1 & 11 & 3,4 \\
\hline Indústria de transformação & 89 & 65,9 & 64 & 68,1 & 204 & 64,0 \\
\hline Alimentos, bebidas e fumo & 21 & 15,6 & 7 & 7,4 & 33 & 10,3 \\
\hline Fab. prod. químicos & 15 & 11,1 & 7 & 7,4 & 24 & 7,5 \\
\hline $\begin{array}{l}\text { Fab. prod. farmoquímicos e } \\
\text { farmacêuticos }\end{array}$ & 13 & 9,6 & 8 & 8,5 & 26 & 8,2 \\
\hline $\begin{array}{l}\text { Fab. equipamentos de } \\
\text { informática, eletrônicos e } \\
\text { óticos }\end{array}$ & 2 & 1,5 & 10 & 10,6 & 22 & 6,9 \\
\hline Eletricidade e gás & 11 & 8,1 & 4 & 4,3 & 23 & 7,2 \\
\hline $\begin{array}{l}\text { Água, esgoto, atividades de } \\
\text { gestão de resíduos, etc. }\end{array}$ & 1 & 0,7 & 2 & 2,1 & 5 & 1,6 \\
\hline Construção civil & 3 & 3,2 & - & - & 4 & 1,3 \\
\hline $\begin{array}{l}\text { Comércio, reparação de veículos e } \\
\text { motocicletas }\end{array}$ & 2 & 1,5 & 1 & 1,1 & 5 & 1,6 \\
\hline Informação e comunicação & 7 & 5,2 & 7 & 7,4 & 21 & 6,6 \\
\hline $\begin{array}{l}\text { At. financeiras, de seguros e } \\
\text { serviços afins }\end{array}$ & 1 & 0,7 & 1 & 1,1 & 2 & 0,6 \\
\hline $\begin{array}{l}\text { At. profissionais, técnicas e } \\
\text { científicas }\end{array}$ & 10 & 7,4 & 3 & 3,2 & 23 & 7,2 \\
\hline $\begin{array}{l}\text { Adm. pública, saúde humana e } \\
\text { serv. sociais }\end{array}$ & 2 & 1,5 & - & - & 3 & 0,9 \\
\hline Total (1) & 135 & 100,0 & 94 & 100,0 & 319 & 100,0 \\
\hline
\end{tabular}

Fonte: BR Survey. Elaboração dos autores.

(1) É considerado o total agregado da indústria de transformação. 
Também se destacaram neste conjunto as empresas de eletricidade e gás $(8,1 \%)$ e de atividades técnicas e científicas (7,4\%). Já entre as empresas que utilizaram recursos próprios e públicos no financiamento da cooperação, sobressaem aquelas da agricultura (5,6\% do total) e, na indústria de transformação, as dos setores de fabricação de equipamentos de informática, eletrônicos e óticos $(6,9 \%),{ }^{9}$ fabricação de produtos farmoquímicos/farmacêuticos (8,2\%), alimentos, bebida e fumo (10,3\%) e fabricação de produtos químicos $(7,5 \%)$. As empresas de informação e comunicação também se salientam neste segundo conjunto, representando 6,6\% do total.

É interessante observar que as empresas dos setores de alimentos, bebidas e fumo e de fabricação de produtos químicos e de produtos farmoquímicos/farmacêuticos se destacam em ambos os conjuntos de empresas, embora suas participações relativas sejam maiores entre aquelas que financiaram a cooperação com universidades/IPPs exclusivamente com recursos próprios.

\subsection{Cooperação entre universidades/IPPs e empresas segundo a natureza da fonte de financiamento}

No que se refere às fontes de informação utilizadas pelas empresas em suas atividades inovativas para completar ou sugerir novos projetos, em cooperação com universidades/IPPs, constata-se que as duas fontes mais citadas por ambos os conjuntos de empresas analisados foram a linha de produção da própria empresa e os clientes (Tabela 8), seguindo padrão observado na Pintec $2008 .{ }^{10}$ Entretanto, as empresas que financiaram seus processos cooperativos com universidades/IPPs com 100\% de recursos próprios atribuíram maior importância à própria linha de produção, enquanto aquelas que utilizaram recursos próprios e públicos apontaram os clientes como a principal fonte de informação para sugerir novos projetos de inovação.

Adicionalmente, os dados da Tabela 8 indicam que as universidades tiveram maior importância, como fonte de informação, para as empresas que financiaram a cooperação com recursos próprios e públicos, ocupando a terceira posição, en-

9 Nesta classificação de atividade econômica (CNAE), inclui-se a indústria de fabricação de equipamentos de informática, beneficiária da Lei de Informática. Cabe salientar que levantamento realizado nos dados do BR Survey mostra que 6 das 11 empresas que utilizaram três tipos de financiamento (público, próprio e de terceiros) são de informática, demonstrando que as empresas desse setor estão se beneficiando das oportunidades que se apresentam para o financiamento de suas atividades inovativas (tanto público, por mecanismos de incentivo, quanto de terceiros, como o capital de risco).

$10 \mathrm{Na}$ Pintec 2008, na indústria, as cinco principais fontes de informação utilizadas foram: redes de informação informatizadas (68,8\%); clientes (68,2\%); fornecedores (65,7\%); áreas internas à empresa (61,5\%); e feiras e exposições $(55,6 \%)$. 
quanto para as que financiaram os projetos de colaboração exclusivamente com recursos próprios foram a quarta fonte de informação para sugerir novos projetos, posteriormente às informações provenientes de outras empresas. Este cenário pode ser resultado da indução das políticas de C,T\&I que, cada vez mais, disponibilizam recursos para projetos de cooperação U-E.

TABELA 8

Empresas brasileiras que responderam ao BR Survey e que financiaram projetos de colaboração com universidades/IPPs, por natureza do financiamento, segundo fontes de informação para sugerir e completar projetos de inovação

2009

\begin{tabular}{|c|c|c|c|c|}
\hline \multirow[b]{2}{*}{ Fontes de informação } & \multicolumn{2}{|c|}{$\begin{array}{c}\text { Somente recursos } \\
\text { próprios }\end{array}$} & \multicolumn{2}{|c|}{$\begin{array}{l}\text { Recursos públicos } \\
\text { e próprios }\end{array}$} \\
\hline & $\begin{array}{c}\text { Sugeriu } \\
\text { novos } \\
\text { projetos }\end{array}$ & $\begin{array}{c}\text { Contribuiu } \\
\text { para } \\
\text { completar } \\
\text { projetos já } \\
\text { existentes }\end{array}$ & $\begin{array}{c}\text { Sugeriu } \\
\text { novos } \\
\text { projetos }\end{array}$ & $\begin{array}{c}\text { Contribuiu } \\
\text { para } \\
\text { completar } \\
\text { projetos já } \\
\text { existentes }\end{array}$ \\
\hline Linha de produção da própria empresa & 71,9 & 71,9 & 69,1 & 77,7 \\
\hline Clientes & 68,1 & 57,0 & 78,7 & 61,7 \\
\hline Outras empresas & 57,8 & 51,9 & 53,2 & 50,0 \\
\hline Universidades & 54,8 & 62,2 & 66,0 & 69,1 \\
\hline $\begin{array}{l}\text { Institutos, Centros e Laboratórios } \\
\text { de Pesquisa }\end{array}$ & 54,8 & 53,3 & 57,4 & 66,0 \\
\hline Internet & 49,6 & 46,7 & 53,2 & 56,4 \\
\hline Feiras e exposições & 48,9 & 47,4 & 61,7 & 52,1 \\
\hline Publicações e relatórios técnicos & 46,7 & 45,2 & 62,8 & 66,0 \\
\hline Sistemas de conhecimento local & 46,7 & 40,7 & 41,5 & 43,6 \\
\hline Concorrentes & 40,7 & 29,6 & 40,4 & 42,6 \\
\hline Fornecedores & 39,3 & 43,0 & 47,9 & 57,4 \\
\hline $\begin{array}{l}\text { Empresas de consultoria ou } \\
\text { contratação de P\&D }\end{array}$ & 28,1 & 26,7 & 35,1 & 34,0 \\
\hline $\begin{array}{l}\text { Atividades cooperativas ou joint } \\
\text { ventures }\end{array}$ & 23,0 & 23,0 & 26,6 & 27,7 \\
\hline Outros & 18,5 & 17,0 & 20,2 & 17,0 \\
\hline Total de empresas entrevistadas & 135 & - & 94 & - \\
\hline
\end{tabular}

Fonte: BR Survey. Elaboração dos autores.

Quando se consideram todas as fontes de informação classificadas como importantes por mais de $50 \%$ das empresas em cada item, tanto para sugerir quanto 
para contribuir com projetos de inovação já existentes, é possível verificar que, em ambos os modos de financiamento utilizados na cooperação com universidades/IPPs, é atribuída grande importância a cinco fontes: própria linha de produção; clientes; outras empresas; universidades; e IPPs. Entretanto, as empresas que utilizaram financiamento próprio e público para a cooperação indicaram grande relevância a outras três fontes para sugerir novos projetos - Internet, feiras e exposições e publicações e relatórios técnicos - e, além destas, os fornecedores, para contribuição com projetos já existentes.

Nesta perspectiva, os dados da Tabela 8 sugerem que as empresas que financiam a cooperação com recursos próprios e públicos atribuem maior importância às universidades como fontes de informação para seus projetos de inovação do que as que financiam a interação com recursos próprios - a diferença chega a 10\% para sugerir novos projetos. Além disso, as empresas com financiamento próprio e público atribuem mais importância a uma maior quantidade de fontes de informação do que aquelas que financiaram seus projetos em cooperação com universidades e IPPs apenas com capital próprio.

Diretamente relacionada à discussão anterior, a Tabela 9 apresenta a importância atribuída pelas empresas aos modos de interação com universidades/IPPs no desenvolvimento das atividades inovativas. Nos dois conjuntos de empresas os modos de interação com universidades/IPPs mais relevantes foram: publicaçôes e relatórios; conferências públicas e encontros; pesquisa realizada em conjunto com a universidade/IPP; e troca informal de informações.

As empresas que financiaram os projetos em colaboração com universidades/ IPPs exclusivamente com recursos próprios atribuíram maior importância às seguintes fontes de informação: conferências públicas e encontros; patentes; e empresa pertencente a uma universidade/IPPs para suas atividades inovativas. Já as empresas que financiaram seus projetos cooperativos com uma composição de recursos próprios e públicos atribuíram maior importância a: pesquisa realizada em conjunto com universidades/IPPs; publicações e relatórios; pesquisa encomendada à universidade/ IPPs; troca informal de informaçōes; consultoria com pesquisadores individuais; pessoal contratado com graduação ou pós-graduação; e intercâmbio temporário de pessoal. Isto sugere que os diversos modos de interação com universidades/IPPs para os processos inovativos das empresas são mais bem avaliados quando estas utilizam também recursos públicos no financiamento da interação. Assim, essas empresas não somente atribuem maior importância a diversos modos de interação, como também o fazem para aqueles relativos à "colaboração universidade-empresa”. 
TABELA 9

Empresas brasileiras que responderam ao BR Survey e que financiaram projetos de colaboração com universidades/IPPs, por natureza do financiamento, segundo modos de interação considerados importantes 2009 (1)

\begin{tabular}{|c|c|c|c|}
\hline & & \multicolumn{2}{|c|}{ Em porcentagen } \\
\hline \multirow{2}{*}{ Tipos } & \multirow{2}{*}{ Modos de interação } & $\begin{array}{l}\text { Somente } \\
\text { recursos } \\
\text { próprios }\end{array}$ & $\begin{array}{c}\text { Recursos } \\
\text { públicos e } \\
\text { próprios }\end{array}$ \\
\hline & & \multicolumn{2}{|c|}{$\begin{array}{l}\text { Moderadamente ou } \\
\text { muito importante }\end{array}$} \\
\hline \multirow{2}{*}{$\begin{array}{l}\text { "Ciência } \\
\text { Aberta" }\end{array}$} & Publicações e relatórios & 62,2 & 68,1 \\
\hline & Conferências públicas e encontros & 60,4 & 55,9 \\
\hline \multirow[t]{2}{*}{ Educação } & $\begin{array}{l}\text { Pessoal contratado com graduação ou pós- } \\
\text { graduação }\end{array}$ & 53,3 & 55,3 \\
\hline & Tecnologia licenciada & 29,3 & 30,3 \\
\hline \multirow[t]{2}{*}{ Comercial } & Patentes & 34,1 & 31,9 \\
\hline & Intercâmbio temporário de pessoal & 27,0 & 33,0 \\
\hline \multirow{10}{*}{$\begin{array}{c}\text { Colaboração } \\
\text { universidade- } \\
\text { empresa }\end{array}$} & Consultoria com pesquisadores individuais & 43,7 & 59,0 \\
\hline & Pesquisa encomendada à universidade/IPP & 49,3 & 64,4 \\
\hline & $\begin{array}{l}\text { Participação em redes que envolvam a } \\
\text { universidade/IPP }\end{array}$ & 46,3 & 50,0 \\
\hline & $\begin{array}{l}\text { Pesquisa realizada em conjunto com a } \\
\text { universidade/IPP }\end{array}$ & 60,0 & 77,1 \\
\hline & Troca informal de informações & 57,0 & 61,2 \\
\hline & Parques científicos e/ou tecnológicos & 31,9 & 31,9 \\
\hline & Incubadoras & 19,3 & 23,4 \\
\hline & Empresa pertence a uma universidade/IPP & 17,0 & 14,4 \\
\hline & Empresa é spin-off da universidade/IPP & 11,1 & 17,6 \\
\hline & Total de empresas entrevistadas & 135 & 94 \\
\hline
\end{tabular}

Fonte: BR Survey. Elaboração dos autores.

(1) Os cálculos percentuais foram realizados por uma regra de três básica, uma vez que as respostas das duas questôes (fontes de informação de universidades/IPPs) foram somadas para as opçōes moderadamente e muito importante e a proporção correta teria de ser mantida.

Adicionalmente, tem-se que as empresas que financiaram a interação com recursos próprios conferiram menor importância a fontes de conhecimento como: 
participação em redes que envolvam a universidade/IPPs; spin-off da universidade/ IPP; tecnologia licenciada; e incubadoras, ${ }^{11}$ que refletem instrumentos de cooperação universidade-empresa de uma visão science-based, muito fomentados pelas políticas recentes.

Outra conclusão que se pode chegar a partir da análise da Tabela 9 é que há semelhança nos modos de interação de empresas de ambos os tipos do financiamento da cooperação com universidade/IPPs, o que tende a acontecer mais por meio dos instrumentos de "ciência aberta" (publicações e relatórios, conferências públicas e encontros) e dos relacionados à missão educacional da universidade (contratação de pessoal com graduação e pós-graduação) e não dos canais "comerciais" (tecnologia licenciada, patentes). Entretanto, o maior percentual de respostas concernentes ao financiamento com recursos públicos e próprios nos modos de interação relacionados à "colaboração universidade-empresa" sinaliza para uma possível indução da política para a utilização destes instrumentos.

A Tabela 10 apresenta as razōes da colaboração de empresas com universidades/IPPs. Em uma perspectiva comparativa entre os dois conjuntos de empresas, observa-se que aquelas que financiaram os projetos de colaboração exclusivamente com recursos próprios atribuíram maior importância à realização de testes necessários para produtos e processos da empresa $(71,1 \%)$ e à transferência de tecnologia $(65,9 \%)$. Isto reforça a argumentação anterior de que estas empresas tendem a buscar na colaboração com universidades/IPPs o conhecimento que contribui diretamente na solução de seus problemas e que são de maior apropriação.

As empresas que utilizaram recursos próprios e públicos no financiamento da cooperação, por sua vez, consideraram mais importante: contratação de pesquisas complementares, necessárias para suas atividades inovativas (78,7\%); utilização de recursos disponíveis nas universidades e laboratórios de pesquisa (76,6\%); contratação de pesquisas que elas não podem realizar $(71,6 \%)$; e realização de testes necessários para produtos e processos da empresa $(70,2 \%)$. Os resultados apontam que este último conjunto de empresas busca mais as universidades/IPPs para a realização de pesquisa em conjunto, o que pode ser resultado da indução via recursos públicos.

11 Destaca-se, contudo, que as empresas de pequeno porte atribuíram maior importância às fontes de informação incubadoras; spin-off das universidades/IPPs; e intercâmbio temporal de pessoal, comparativamente às médias empresas, o que é explicado pela relevância que estes mecanismos podem ter no seu surgimento e crescimento. 
TABELA 10

Empresas brasileiras que responderam ao BR Survey e que financiaram projetos de colaboração com universidades/IPPs, por natureza do financiamento, segundo razões da colaboração 2009

\begin{tabular}{|c|c|c|}
\hline & & Em porcenta \\
\hline \multirow[t]{2}{*}{ Razões da colaboração } & $\begin{array}{l}\text { Somente } \\
\text { recursos } \\
\text { próprios }\end{array}$ & $\begin{array}{l}\text { Recursos } \\
\text { públicos e } \\
\text { próprios }\end{array}$ \\
\hline & \multicolumn{2}{|c|}{$\begin{array}{l}\text { Moderadamente ou muito } \\
\text { Importante }\end{array}$} \\
\hline
\end{tabular}

Transferência de tecnologia da universidade

65,9

63,8

Buscar conselhos de cunho tecnológico ou consultoria com pesquisadores e/ou professores p/ a solução de problemas relacionados à produção

Aumentar a habilidade da empresa para encontrar e absorver informações tecnológicas

Conseguir informações sobre engenheiros ou cientistas e/ ou tendências de P\&D nas áreas científicas

Contratar pesquisas complementares, necessárias para as atividades inovativas da empresa, em universidades/IPPs

Contratar pesquisas que a empresa não pode realizar

Fazer, o mais cedo possível, contatos com estudantes universitários de excelência para futuro recrutamento

Utilizar recursos disponíveis nas universidades e laboratórios de pesquisa

Realizar testes necessários para produtos e processos da empresa

Fonte: BR Survey. Elaboração dos autores. 


\section{Considerações finais}

Este trabalho apresentou evidências empíricas recentes de pesquisa realizada com empresas no que tange à natureza da fonte de financiamento da cooperação U-E. Diferentemente de estudos anteriores, que focaram na análise de instrumentos e/ou projetos de financiamento, ou se restringiram a estudos de casos (ARAUJO, 2007) ou a um setor industrial (PARANHOS, 2010), este trabalho analisou as respostas de 319 empresas de diferentes portes e origem do capital, distribuídas em diferentes setores de atividade.

A análise das empresas que financiaram com $100 \%$ de recursos próprios os projetos em cooperação com universidades/IPPs sugere que tais empresas tendem a valorizar mais esse elemento constituinte do sistema nacional de inovação na conclusão de projetos existentes, bem como os mecanismos mais diretos de interação, de direta aplicação aos problemas existentes e que possibilitam maior apropriação dos resultados. Isto é coerente com o esforço de inovação, voltado para melhorias incrementais, e a disposição de aplicar recursos próprios em atividades de menor custo e risco, ou em que há maior possibilidade de gerenciar o risco.

Nessa perspectiva, os resultados do BR Survey são coerentes com as informaçôes da Pintec 2008, que demonstram que o dispêndio das atividades inovativas das empresas é preponderantemente voltado à aquisição de máquinas e equipamentos, em detrimento das atividades de P\&D internas e externas. Este perfil do esforço inovativo no Brasil condiz com o predomínio de inovaçôes de processos e de produtos já existentes (isto é, não são novos para o mercado). A análise comparativa das fontes de informação relevantes para sugerir e completar projetos de inovação, dos modos de interação e da motivação para a colaboração dos dois conjuntos de empresas aqui analisados aponta que a natureza do financiamento da cooperação parece não interferir nos dois primeiros aspectos, entretanto, isso ocorre para motivação ou objetivos da interação. Assim como as fontes de informação mais importantes, para ambos os tipos de empresas, são a linha de produção, clientes e universidades, os modos de interação mais frequentes tendem a ser aqueles relacionados à "ciência aberta", isto é, aos mecanismos habitualmente utilizados pelas universidades e que, inclusive, fazem parte da sua lógica de funcionamento (como é o caso das publicações, encontros e conferências). Entretanto, é possível observar que as empresas que utilizam recursos próprios e públicos para financiar a cooperação, no geral, valorizam mais informação de diversas fontes, incluindo aquelas referentes às uni- 
versidades/IPPs, bem como variados modos de interação, em especial os referentes à "colaboração universidade-empresa".

Por sua vez, as evidências do BR Survey indicam que a natureza do financiamento parece influenciar os objetivos (ou motivação) da cooperação entre empresas e universidades/IPPs. A disponibilidade de recurso público parece induzir as empresas a participarem de projetos cooperativos de maiores risco e custo. Ademais, conforme mencionado na revisão da literatura, projetos pouco ambiciosos em termos de resultados de P\&D e de pouca densidade tecnológica dificilmente são financiados com recursos públicos, justificando a preponderância do financiamento privado. Desta forma, mantém-se como necessária a atuação pública no fomento a determinados mecanismos de incentivo à inovação de maior risco e de efeito de transbordamento mais elevado, que tendem a ter um menor comprometimento privado.

Nesta perspectiva, a composição de financiamento público parece importante para induzir parcerias que envolvam maiores complexidade e risco. Além disso, o financiamento público é importante para estimular parcerias das empresas com universidades/IPPs, que podem perdurar mesmo após o termino do financiamento, conforme ilustrado pela análise de Salles Filho (2011). Desta forma, os resultados preliminares do trabalho reforçam a argumentação de que os incentivos governamentais à cooperação universidade-empresa sejam focados no fomento a parcerias que envolvam maior risco, custo e complexidade e que dificilmente seriam financiados com recursos das empresas. Isso poderia tornar os programas de estímulo à interação entre empresas e universidades/IPPs mais efetivos em seus impactos.

\section{Referências bibliográficas}

ARAUJO, A. L. How institutions shape the formation of $R \& D$ partnerships - evidence from Brazil. Master's Dissertation. Alborg: Aalborg University, 2007.

AROCENA, R.; SUTZ, J. Knowledge, innovation and learning: systems and policies in the north and in the south. In: CASSIOLATO, J. E. et al. (eds.) Systems of Innovation and development - evidence from Brazil. Edward Elgar, 2003. 
ARROW, K. J. Economic welfare and the allocation of resources for invention. In: NELSON, R. The rate and direction of inventive activity. NBER: Princeton University Press, 1962, p. 609-629.

BALÁZS, K.; PLONSKI, A. Academic-industry relations in middle-income countries: East Europe and Ibero-America. Science and Public Policy, v. 21, n. 2, p. 109-116, 1994.

BRISOLLA, S; CORDER, S.; GOMES, E.; MELLO, D. As relações universidade-empresagoverno: um estudo sobre a Universidade Estadual de Campinas. Educação \& Sociedade, ano XVIII, n. 61, dezembro 1997.

CALZOLAIO, A; DATHEIN, R. Políticas fiscais de incentivo à inovação: uma avaliação da Lei do Bem. In: XV ENCONTRO DE ECONOMIA DA REGIÃO SUL - ANPEC. Porto Alegre, 2012.

CHRISTENSEN, J. L. The role of finance in national system of innovation. In: LUNDVALL, B. National systems of innovation. London: Pinter Publishers, 1992.

COHEN, W.; NELSON, R; WALSH, J. Links and impacts: the influence of public R\&D on industrial research. Management Science, v. 48, n. 1, p. 1-23, 2002.

DE NEGRI, F; ALVES, P.; KUBOTA, L. C.; CAVALCANTE, L. R.; DAMASCENO, E. Perfil das empresas integradas ao Sistema Federal de C\&T\&I no Brasil e aos Fundos Setoriais: uma análise exploratória. Relatório de Pesquisa do Projeto Metodologia de Avaliação de Resultados de Conjuntos de Projetos Apoiados por Fundos Públicos de Ciência, Tecnologia e Inovação (C\&T\&I). Brasília: Ipea, 2010.

FERNANDES, A. C; SOUZA, B.; SILVA, A.; SUZIGAN, W.; CHAVES, C.; ALBUQUERQUE, E. Academy-industry links in Brazil: evidence about channels and benefits for firms and researchers. Science and Public Policy, v. 37, n. 7, August 2010.

FRENKEL, J. Sistemas de apoio fiscal-crediticio ao risco tecnológico e à competitividade. Estudo da competitividade da induistria brasileira. Campinas: Unicamp, 1993.

FREEMAN, C.; SOETE, L. The economics of industrial innovation. Cambridge, Massachusetts: The MIT Press, 1997.

GUINET, J. National systems for financing innovation. Paris: Head of Publications Service, OCDE, 1995.

GUSSONI, M.; MANGANI, A. R\&D cooperation, appropriability and public funding: an empirical investigation. In: 37 EARIE ANNUAL CONFERENCE. Istanbul, Turkey, September 2010. Disponível em: <http://www.earie2010.org/>.

IBGE. Pesquisa de Inovação Tecnológica 2008. Rio de Janeiro, 2010. 
KLEVORICK, A. K; LEVIN, R.; NELSON, R.; WINTER, S. On the sources and significance of inter-industry differences in technological opportunities. Research Policy, v. 24, n. 2, p. 185-205, March 1995.

MORAIS, J. M. Os fundos setoriais e as tendências recentes de programas de subvenção econômica às empresas na FINEP. Relatório de Pesquisa do Projeto Metodologia de Avaliação de Resultados de Conjuntos de Projetos Apoiados por Fundos Públicos de Ciência, Tecnologia e Inovação (C\&T\&I). Brasília: Ipea, 2010

MOWERY, D. C.; SAMPAT, B. N. Universities in national innovation systems. In: FAGERBERG, J.; MOWERY, D. C.; NELSON, R. R. (Orgs.) The Oxford handbook of innovation. Oxford: Oxford University Press, 2005.

NELSON, R. Capitalism as an engine of progress. Research Policy, v. 19, n. 3, p. 193-214, June 1990.

PARANHOS, J. Interação entre empresas e instituiçôes de ciência e tecnologia no sistema farmacêutico de inovação brasileira: estrutura, conteúdo e dinâmica. Tese (Doutorado). Rio de Janeiro: IE/UFRJ, 2010.

RAPINI, M.; ALBUQUERQUE, E; CHAVES, C.; SILVA, L.; SOUZA, S.; RIGHI, H.; CRUZ, W. University-industry interactions in an immature system of innovation: evidence from Minas Gerais, Brazil Science and Public Policy, v. 36, n. 5, p. 373-386, June 2009.

RAPINI, M.; OLIVEIRA, V. Remuneração dos relacionamentos dos grupos de pesquisa do CNPq com o setor produtivo. Relatório de Pesquisa do Projeto Metodologia de Avaliação de Resultados de Conjuntos de Projetos Apoiados por Fundos Públicos de Ciência, Tecnologia e Inovação (C\&T\&I). Belo Horizonte: Cedeplar, 2012.

ROSENBERG, N. Scientific instrumentation and univeristy research. Research Policy, v. 21, n. 4, p. 381-390, August 1992.

ROSENBERG, N; NELSON, R. American university and technical advance in industry. Research Policy, v. 23, n. 3, p. 323-348, May1994.

SALLES FILHO, S. Quanto vale o investimento em ciência, tecnologia e inovaçãa? ComCiência, n. 129, 10/06/2011. Disponível em: <http://www.comciencia.br/comciencia/ ?section=8\&edicao=67\&id=848>. Acesso em: $01 \mathrm{dez} .2011$.

SCHIMANK, U. The contribution of university research to the technological innovation of the German economy: societal auto-dynamic and political guidance. Research Policy, v. 17, p. 329-340, 1988.

SUZIGAN, W.; ALBUQUERQUE, E. M. The underestimated role of universities for development. Brazilian Journal of Political Economy, v. 31, n. 1, p. 3-30, Jan./Mar. 2011. 
A natureza do financiamento influencia na interação universidade-empresa no Brasil?

SUZIGAN, W.; ALBUQUEQUE, E.; GARCIA, R.; RAPINI, M. University and industry linkages in Brazil: some preliminary and descriptive results. Seoul Journal of Economics, v. 22, n. 4, Winter 2009.

VARGA, A. Regional economic effects of university research: a survey. Department for Economics Geography and Geoinformatics, University of Economics and Business Administration, Vienna, 1997 (Working paper).

WEBSTER, A. Bridging institutions: the role of contract research organizations in technology transfer. Science and Public Policy, v. 21, n. 2, p. 89-97, April 1994.

ENDEREÇOS PARA CORRESPONDENCIA

Márcia Siqueira Rapini-msrapini@cedeplar.ufmg.br Cedeplar/ UFMG - Universidade Federal de Minas Gerais Avenida Antônio Carlos, 6627, sala 3101 31270-901 - Belo Horizonte (MG), Brasil

Vanessa Parreiras de Oliveira - vparreiras@uol.com.br Instituto de Economia/Universidade Estadual de Campinas Rua Pitágoras, 353

13083-857 - Campinas (SP), Brasil

Fábio Chaves do Couto e Silva Neto - fabioi.chaves@gmail.com Instituto de Geociências/ Universidade Estadual de Campinas Rua João Pandiá Calógeras, 51 13083-870 - Campinas (SP), Brasil 
